\title{
1 Factors required for adhesion of Salmonella enterica serovar Typhimurium to \\ 2 lettuce (Lactuca sativa)
}

3

$4 \quad$ Laura Elpers ${ }^{1}$, Michael Hensel ${ }^{1,2}$

$5 \quad{ }^{1}$ Abt. Mikrobiologie, ${ }^{2}$ CellNanOs - Center for Cellular Nanoanalytics

6 Universität Osnabrück, Osnabrück, Germany

7 ORCID 0000-0003-0491-6211 (LE), ORCID 0000-0001-6604-6253 (MH)

8

10 Running title: Salmonella Typhimurium adhesion to lettuce

11 Keywords: adhesiome, Salmonella enterica serovar Typhimurium, lettuce, Lactuca sativa, Lpf

12 fimbriae, Sti fimbriae, MisL, BapA, LPS, flagella-mediated motility

14 Address for correspondence:

15 Michael Hensel

16 Abteilung Mikrobiologie

17 CellNanOs - Center for Cellular Nanoanalytics Osnabrück

18 Fachbereich Biologie/Chemie, Universität Osnabrück

19 Barbarastr. 11

2049076 Osnabrück, Germany

$21 \quad$ Tel: ++ $49(0) 5419693940$

22 Fax: ++ 49 (0)5419693942

23 E-mail: Michael.Hensel@uni-osnabrueck.de 
03.04.2020

Salmonella Typhimurium adhesion to lettuce

\section{Abstract}

26 Salmonella enterica serovar Typhimurium (STM) is a major cause of food-borne gastroenteritis.

27 Recent outbreaks of infections by STM are often associated with non-animal related food, i.e.

28 vegetables, fruits, herbs, sprouts and nuts. One main problem related to consumption of fresh 29 produce is the minimal processing, especially for leafy salads such as corn salad, rocket salad, or

30 lettuce. In this study, we focused on lettuce (Lactuca sativa) which is contaminated by STM at 31 higher rates compared to corn salad, resulting in prolonged persistence. We previously described 32 the contribution of Saf fimbriae, type 1 secretion system (T1SS)-secreted BapA, intact LPS, and 33 flagella-mediated motility to adhesion to corn salad leaves. We systematically analyzed factors 34 contributing to adhesion of STM to lettuce leaves. We used the previously established 35 reductionist, synthetic approach to identify factors that contribute to the surface binding of STM 36 to leaves of lettuce by expressing all known adhesive structure by the Tet-on system. The 37 analyses revealed contributions of Lpf fimbriae, Sti fimbriae, autotransported adhesin MisL, 38 T1SS-secreted BapA, intact LPS, and flagella-mediated motility to adhesion of STM to lettuce 39 leaves. In addition, we identified BapA is a potential adhesin involved in binding to corn salad 40 and lettuce leaf surfaces.

\section{Importance}

42 Gastrointestinal pathogens can be transmitted by animal products, as well as by fresh produce of 43 non-animal origin. The numbers of outbreaks by fresh produce contaminated with gastrointestinal

44 pathogens are increasing, and underline the relevance to human health. The mechanisms involved 45 in the colonization of, persistence on, and transmission by fresh produce are poorly understood 46 and have to be part of further research. Here, we investigated the contribution of adhesive factors 47 of STM in the initial phase of plant colonization, i.e. the binding to the plant surface. Usage of a 
bioRxiv preprint doi: https://doi.org/10.1101/2020.04.03.024968; this version posted April 5, 2020. The copyright holder for this preprint (which was not certified by peer review) is the author/funder, who has granted bioRxiv a license to display the preprint in perpetuity. It is made available under aCC-BY-NC-ND 4.0 International license.

03.04 .2020

Salmonella Typhimurium adhesion to lettuce

48 reductionist, synthetic approach including the controlled surface expression of specific adhesive

49 structures of STM, one at a time, allowed the determination of relevant fimbrial and non-fimbrial

50 adhesins, the O-antigen of lipopolysaccharide, the flagella, and chemotaxis to binding to lettuce

51 leaves.

52 
03.04.2020

Salmonella Typhimurium adhesion to lettuce

\section{Introduction}

54 Salmonella enterica is a common cause of food-borne gastroenteritis leading to thousands of fatal

55 cases worldwide (1). Currently, the numbers of outbreaks of S. enterica infections associated

56 with consumption of fresh produce are increasing (2). Besides contaminated products of animal

57 origin, i.e. eggs, chicken or pork, fresh produce like vegetables, fruits, salads, herbs, and nuts

58 may be contaminated by S. enterica (3). Contamination can occur during pre-harvest by the seeds

59 themselves, by irrigation water, or by fertilizers (often based on animal source). After harvest,

60 fresh produce may be contaminated by improper implemented hygiene regulations, or additional

61 processing steps (washing water, cutting). After first attachment and adhesion, S. enterica can

62 colonize and persist in and on plants, leading to possible replication and further spreading (4).

63 Several studies investigated the interaction of S. enterica and various salad species, thereby

64 focusing on the important first contact of S. enterica to salad. It was shown that S. enterica

65 serovar Thompson adheres to spinach leaves in higher numbers compared to watercress leaves.

66 Attachment to abaxial and adaxial leaf surfaces was comparable (5). Differences in attachment

67 levels to various salad species were further investigated for S. enterica serovar Typhimurium

68 (STM). Adhesion of STM to lettuce leaves occurred in higher numbers compared to corn salad

69 leaves, moreover persistence in planta was longer for lettuce than for corn salad (6).

70 For the adhesion of S. enterica to salad, different factors have been investigated, i.e. involvement

71 of flagella. Directed motility is involved in adhesion to iceberg lettuce leaves while loss of

72 flagella filaments ablated binding of STM. The binding of a smooth swimming $\Delta$ cheY strain was

73 not affected, whereas the internalization was prevented (7). Other studies addressed the

74 involvement of genes in long-term persistence on lettuce leaves under cold storage. Work of Y.

75 Kroupitski et al. (8) revealed a possible involvement of bcsA, misL and yidR due to decreased 
03.04.2020

Salmonella Typhimurium adhesion to lettuce

76 attachment to lettuce leaves and decreased survival during cold storage for respective mutant

77 strains.

78 Investigations of Salmonella-plant interactions are complex, since different sites of contamination

79 (roots, leaves, fruits, seeds), age of leaves, and possible also roots, fruits and seeds, metabolic

80 changes of plants during dark-night rhythm, varying temperatures, and other environmental

81 stresses (e.g. UV light) have to be considered. Here, we focus on the adhesion of STM to lettuce

82 leaves, and aim to reveal factors involved in initial colonization and Salmonella-plant interaction.

83 While previous studies mainly investigated STM WT, or strains mutated in candidate adhesion

84 factors, we focus on expression of defined adhesive structures, one at a time, to reveal possible

85 ligands on lettuce leave surfaces.

86 STM possesses a complex set of adhesive structures including 12 chaperone-usher (C/U)

87 fimbriae, curli fimbriae assembled by the nucleation-precipitation pathway, two type 1 secretion

88 system (T1SS)-secreted adhesins (BapA, SiiE), three type 5 secretion system (T5SS)-secreted

89 (autotransported) adhesins (MisL, ShdA, SadA), and two outer membrane proteins (OMPs) with

90 putative adhesive features (PagN and Rck) $(9,10)$. For most $\mathrm{C} / \mathrm{U}$ fimbriae, little is known about

91 conditions of native expression and binding properties (11). All operons encoding $\mathrm{C} / \mathrm{U}$ fimbriae

92 consists at least of a fimbrial main subunit, a specific periplasmic chaperone, and an usher located

93 in the outer membrane (12). Best characterized $\mathrm{C} / \mathrm{U}$ fimbriae so far are the mannose-sensitive

94 type 1 fimbriae encoded by fimAICDHF (13), and pef fimbriae encoded by genes on pSLT2. Pef

95 fimbriae are involved in the binding to $\mathrm{Le}^{\mathrm{x}}$ blood group antigen and in the formation of biofilm

96 on chicken intestinal epithelium $(14,15)$. Curli fimbriae are encoded by two operons $\operatorname{csg} B A C$ and

$97 \operatorname{csg} D E F G$, and are assembled by the nucleation-precipitation pathway. Curli fimbriae are known

98 to be involved in the formation of biofilms together with cellulose $(16,17)$. 
bioRxiv preprint doi: https://doi.org/10.1101/2020.04.03.024968; this version posted April 5, 2020. The copyright holder for this preprint (which

was not certified by peer review) is the author/funder, who has granted bioRxiv a license to display the preprint in perpetuity. It is made available under aCC-BY-NC-ND 4.0 International license.

03.04.2020

Salmonella Typhimurium adhesion to lettuce

99 The Salmonella pathogenicity island 4 (SPI4) locus (siiABCDEF) encodes the T1SS (SiiCDF)

100 which mediates the secretion and surface expression of giant adhesin SiiE on the bacterial surface

101 (18). SiiE consists of 53 repetitive bacterial Ig domains (BIg) and is the largest protein in STM

102 with a molecular mass of $595 \mathrm{kDa}$. SiiE specifically binds glycostructures with N-

103 acetylglucosamine (GlcNAc) or 2,3-linked sialic acid (19). SiiE mediates the first contact of STM

104 to polarized epithelial cells, which is followed by invasion mediated by the SPI1-encoded T3SS

105 and various effector proteins $(20,21)$. The other T1SS-secreted adhesin BapA (386 kDa) is

106 encoded by bapABCD (biofilm associated protein), contains $28 \mathrm{BIg}$ domains, and is involved in

107 biofilm formation $(17,22)$. The T1SS for surface expression of BapA is composed of BapBCD.

108 STM possesses two monomeric autotransporters (MisL and ShdA) and one trimeric

109 autotransporter (SadA). These autotransporters are not expressed under laboratory conditions and

110 little is known about their native expression (23). The monomeric autotransporters MisL and

111 ShdA are known to bind fibronectin, thus being involved in the intestinal infection of mice (24-

112 26). SadA of STM strain SL1344 is possibly involved in biofilm formation and adhesion to

$113 \mathrm{CaCo} 2$ cells but only in a strain with altered lipopolysaccharide (LPS) (27). In addition to

114 adhesins proper, as possible factors involved in adhesion to lettuce leaves LPS, flagella filament

115 and motility were considered.

116 For most adhesins, general environmental or host factors inducing expression are not known.

117 Therefore, we used a synthetic system based on the tetA promoter for controlled expression of

118 various STM adhesins (23). We tested the adhesive structures for involvement in binding to

119 lettuce leave surfaces by a reductionist approach described before (28). Our data will support the

120 classification of adhesive structures commonly involved in binding to salad species, in order to

121 subsequently develop strategies for prevention or reduction of adhesion of S. enterica to salad 122 leaves. 
03.04.2020

Salmonella Typhimurium adhesion to lettuce

\section{Results}

125 In a previous study (28) we deployed a reductionist, synthetic approach to identify factors that

126 contribute to the surface binding of STM to leaves of corn salad. We now investigate factors that

127 contribute to surface binding of STM to leaves of lettuce. Infection of corn salad and lettuce

128 grown under aseptic conditions with STM indeed revealed a higher adhesion of STM to lettuce

129 (Figure S1B). To identify adhesive structures required for adhesion to multiple or individual

130 salad species, we investigated the complex adhesiome of STM in its entirety.

131 Various databases such as GEO, SalCom, and others $(6,29,30)$ were used to identify potential

132 environmental stimuli that induce expression of STM adhesins. However, these analyses only

133 revealed defined culture conditions leading to expression of 3 (i.e. Saf, Sii, PagN) of 20 adhesins

134 in the STM adhesiome (Janina Noster, MH, data not shown). The rather diverse nature of these

135 inducing conditions excluded a systemic comparison. Therefore, we expressed various adhesins

136 ectopically under control of the tetR $\mathrm{P}_{t e t A}$ cassette as previously described (23). To avoid

137 interference with native expression of certain adhesins, we decided to use strain SR11 $\Delta 12$

138 lacking all $12 \mathrm{C} / \mathrm{U}$ fimbriae. STM SR11 $\Delta 12$ strains harboring plasmids for expression of various

139 adhesins were tested for contribution to adhesion to lettuce by validating the level of adhesion.

140 Further, we tested strains lacking further putative adhesion factors. These strains included defects

141 in flagella assembly and motility, in LPS structure, and a strain lacking all 20 known adhesive

142 structures $(\triangle 12 \Delta m i s L \triangle s a d A \triangle s h d A \triangle$ SPI4 $\triangle$ bapABCD $\triangle r c k \triangle p a g N \triangle c s g B A C-D E F G=$ SR11 $\Delta 20)$.

143 Adhesion assays with lettuce leaves revealed no differences in adhesion for SR11 WT and the

144 used background SR11 $\Delta 12$ lacking all $12 \mathrm{C} / \mathrm{U}$ fimbriae (Figure S1A). Furthermore, the deletion

145 of all putative adhesive structures, strains SR11 $\Delta 20$ was not altered in adhesion compared to

146 SR11 112 (Figure S1C). 
bioRxiv preprint doi: https://doi.org/10.1101/2020.04.03.024968; this version posted April 5, 2020. The copyright holder for this preprint (which

was not certified by peer review) is the author/funder, who has granted bioRxiv a license to display the preprint in perpetuity. It is made available under aCC-BY-NC-ND 4.0 International license.

03.04.2020

Salmonella Typhimurium adhesion to lettuce

\section{Contribution of fimbrial adhesins to adhesion to lettuce}

148 We analyzed adhesion to lettuce by anhydrotetracycline (AHT)-induced expression of all C/U

149 fimbriae encoded by STM. Different levels of binding to lettuce leaves were mediated by

150 expression of $\mathrm{C} / \mathrm{U}$ fimbriae (Figure 2A). Expression of Bcf, Sth, Pef, Stb and Stj did not affect

151 adhesion compared to background strain SR11 $\Delta 12$. Therefore, cognate ligands may be absent on

152 lettuce leaves. The expression of Fim, Saf, Stc, Std and Stf fimbriae led to decreased adhesion

$153(47 \%, 73 \%, 59 \%, 76 \%$, and 72\% mean, respectively). However, SR11 $\Delta 12$ harboring plasmids

154 encoding for Saf, Stc and Stf fimbriae also resulted in decreased adhesion in the absence of

155 inducer AHT. In absence of AHT no synthesis and transport to bacterial surface of these three

156 fimbriae were observed by flow cytometry (23). Expression of Lpf and Sti fimbriae resulted in

157 significantly increased adhesion to lettuce (means of $167 \%$ and $139 \%$, respectively). Non-

158 induced controls for Lpf and Sti fimbriae showed similar adhesion compared to background

159 SR11 $\Delta 12$. Hence, we propose cognate ligands on lettuce leaves for Lpf and Sti fimbriae. AHT-

160 induced expression of curli fimbriae led did not alter adhesion (Figure 2Error! Reference source

161 not found.B), whereas the deletion of $\operatorname{csg} B A C$ and $\operatorname{csg} D E F G$ resulted a significantly increased

162 adhesion to lettuce (131\% mean).

163 Contribution of T1SS-secreted non-fimbrial adhesins to adhesion to lettuce

164 A small subpopulation of STM expresses SiiE under laboratory conditions (3.5 h subculture in

165 LB). Enhanced surface expression of SiiE was achieved by AHT-induced expression of hilD, the

166 central transcriptional activator of SPI1/SPI4 genes (31), as generation of a vector for Tet-on

167 expression of the sii operon failed. The frequency of SiiE-expressing STM increased from 168 approximately $12 \%$ under native conditions, to over $80 \%$ after AHT-induced hilD expression

169 (28). The increased surface expression of SiiE in SR11 $\Delta 12$ correlated with significantly 170 decreased adhesion to lettuce (Figure 3A), while a SPI4-deletion strain showed significantly 
bioRxiv preprint doi: https://doi.org/10.1101/2020.04.03.024968; this version posted April 5, 2020. The copyright holder for this preprint (which

was not certified by peer review) is the author/funder, who has granted bioRxiv a license to display the preprint in perpetuity. It is made available under aCC-BY-NC-ND 4.0 International license.

03.04.2020

Salmonella Typhimurium adhesion to lettuce

171 increased adhesion. Since hilD expression also affects the expression of SPI1 and associated

172 effector proteins, we tested the expression of hilD in strains harboring deletions in SPI4 or $\Delta i n v C$,

173 encoding the ATPase subunit of SPI1-T3SS. In both cases, neither the increased expression of

174 SPI1-T3SS genes in STM $\Delta$ SPI4, nor the increased expression of SPI4 genes in $\Delta i n v C$ led to

175 altered adhesion compared to background strain SR11 $\Delta 12$. Therefore, possibly the increased

176 simultaneous expression of genes in SPI4 and SPI1 impaired adhesion to lettuce leaves.

177 AHT-induced expression of bapABCD led to significantly increased adhesion to lettuce, whereas

178 deletion of bapABCD did not affect adhesion (Figure 3B). To achieve a better understanding of

179 BapA binding to lettuce leaves, we used various truncated forms of BapA (28). Alleles of bapA

180 with deletions of BIg1, BIg28, or BIg1-28 were expressed by AHT induction. Synthesis and

181 secretion of mutant forms of BapA were confirmed by flow cytometry in prior work (28), and

182 revealed that deletion of BIg1-28 ablated surface expression of BapA. The deletion of BIg1

183 showed a similar significantly increased adhesion as observed before for full-length BapA,

184 indicating no contribution of BIg1 in adhesion to lettuce. Further, deletion of BIg28 resulted in

185 adhesion comparable to background strain SR11 $\Delta 12$. Thus, deletion of only one BIg domain can

186 be critical for enhanced adhesion of STM by BapA to lettuce. Deletion of BIg1-28 resulted in

187 adhesion comparable to background strain SR11 $\Delta 12$, which is in line with loss of BapA surface

188 expression.

189 Contribution of autotransported adhesins to adhesion to lettuce

190 The AHT-induced expression of shdA led to a significantly decreased adhesion to lettuce leaves

191 (75\% mean, Figure 4A), as well as deletion of $s h d A$ (63\% in average). AHT-induced expression

192 of sadA did not alter adhesion to lettuce, but deletion of sadA resulted in significantly reduced 193 adhesion (77\% in average). The AHT-induced expression of misL revealed a significant increased 
03.04.2020

Salmonella Typhimurium adhesion to lettuce

194 adhesion to lettuce compared to background strain SR11 $\Delta 12$ (Figure 4B). To gain further insight

195 into the contribution of MisL in binding to lettuce leaves, we decided to test truncated forms of

196 MisL in adhesion to lettuce. MisL contains of a cleavable signal sequence (aa1-28) sec-dependent

197 secretion into periplasm, a translocation domain (aa677-955) forming a $\beta$-barrel in the outer

198 membrane and mediating transport of the passenger domain (aa29-676) across the outer

199 membrane. The passenger domain is further divided into a non-conserved region and a conserved

200 region compared to other, non-protease autotransported adhesins (24). C. W. Dorsey et al. (24)

201 revealed that the non-conserved passenger domain (aa29-281) is responsible for binding of MisL

202 to fibronectin, and with lower affinity to collagen IV. Our truncated forms of MisL included a

203 partial deletion of the non-conserved portion of the passenger domain (aa29-227), and a larger

204 deletion of the entire passenger domain (aa29-479). Synthesis and secretion of truncated forms of

205 MisL was confirmed by flow cytometry (Figure S2AB). Furthermore, potential effects on

206 bacterial autoaggregation were investigated by microscopy (Figure S2C) and revealed lack of

207 bacterial autoaggregation with or without AHT induction. Expression of truncated misL $\Delta 29-227$

208 and misL $\Delta 29-479$ revealed no increased adhesion to lettuce (Figure 4B).

209 In conclusion, the non-conserved region of MisL involved in binding to mammalian fibronectin

210 and collagen IV is presumably also involved in the binding to lettuce leaves. Whether the

211 impaired binding of truncated MisL is provoked by the fact that the fibronectin and/or collagen

212 IV binding site is lost, or by the fact that truncated MisL has severely altered conformation has to

213 be further investigated. Besides induced synthesis of MisL, deletion of misL also led to a

214 significant increased adhesion to lettuce compared to background strain SR11 $\Delta 12$. However,

215 STM $\Delta m i s L$ did not reach adhesion as observed for MisL synthesis.

216 Contribution of OMP adhesins to adhesion to lettuce 
bioRxiv preprint doi: https://doi.org/10.1101/2020.04.03.024968; this version posted April 5, 2020. The copyright holder for this preprint (which

was not certified by peer review) is the author/funder, who has granted bioRxiv a license to display the preprint in perpetuity. It is made available under aCC-BY-NC-ND 4.0 International license.

03.04.2020

Salmonella Typhimurium adhesion to lettuce

217 In addition to SPI1-T3SS-mediated invasion of non-phagocytic cells by STM, two outer

218 membrane proteins (OMPs) PagN and Rck were reported to mediate SPI1-T3SS-independent,

219 zipper-like invasion $(32,33)$. Adhesive properties of these OMPs were proposed, which might

220 also affect adhesion to non-mammalian organisms. AHT-induced expression of Rck, as well as

221 deletion of $r c k$ resulted in no altered adhesion to lettuce leaves (Figure 4D). Expression of pagN

222 led to a significantly reduced adhesion (52\% mean), which was also observed for the non-induced

223 samples (67\% mean). However, Western blot analyses confirmed absence of PagN in non-

224 induced cultures (23). In addition, a strain defective in pagN revealed a significantly reduced

225 adhesion (43\% mean).

226

Contribution of flagella filaments and motility to adhesion to lettuce

227 Previous studies revealed contribution of flagella filaments and motility of STM in adhesion to

228 various plant species $(7,34,35)$. Here, we investigate the binding properties of the flagella

229 filament, and the contribution of motility in the adhesion to lettuce leaves by using four distinct

230 deletion strains. Loss of the flagella filaments $(\Delta f l i C \Delta f l j B)$ resulted in significantly decreased

231 adhesion to lettuce leaves (37\% mean, Figure 5A). To bypass reduced interaction with leaf

232 surfaces possibly resulting from loss of motility, contact was forced by centrifugation ( 5 min at

$233500 \mathrm{x} \mathrm{g}$ ). However, centrifugation did not restore adhesion of STM to leaf surfaces (41\% mean).

234 To analyze the contribution of flagella filaments as putative adhesive structure, we used SR11

$235 \triangle 12 \triangle m o t A B$ defective in the energization of the flagella motor, but still harboring flagella

236 filaments. This strain revealed significantly reduced adhesion in static and centrifuged samples

237 (41\% and $42 \%$ means, respectively). Therefore, presence of flagella filaments without rotation is

238 not sufficient for adhesion to lettuce. Deletion of cheZ, resulting in tumbling only, also exhibited

239 a significantly decreased adhesion to lettuce (static $45 \%$ and centrifuged $50 \%$ mean). A strain

240 defective in cheY, restricted to smooth swimming, showed a slight but non-significantly 
03.04.2020

Salmonella Typhimurium adhesion to lettuce

241 decreased adhesion to lettuce leaves under static conditions (87\% mean). After centrifugation, no

242 altered adhesion (111\% mean) was detected for $\Delta c h e Y$ compared to parental strain SR11 $\Delta 12$.

243 Thus, we conclude a contribution of chemotactic motility of STM for adhesion to lettuce leaves.

244 Contribution of $O$-antigen to adhesion to lettuce

245 A main constituent of the bacterial cell envelope is LPS that stabilizes the cell envelope and

246 protects Gram-negative bacteria against various environmental factors. Furthermore, LPS

247 increases the negative charge of the cell envelope, and a putative adhesive role was reported (36).

248 To analyze the contribution of LPS in adhesion to lettuce leaves, we used mutant strains lacking

249 various genes involved in the biosynthesis and control of modal repeats of O-antigen (OAg) of

250 LPS. In STM WT, a heterogeneous distribution of short chain OAg, long chain OAg (L-OAg),

251 and very long chain OAg (VL-OAg) is found. Deletion of $w z z$ results in the homogenous

252 distribution of only VL-OAg, whereas in STM $\Delta f e p E$ a homogenous distribution of only L-OAg

253 is present. A strain defective in both genes $(\Delta w z z \Delta f e p E)$ only possesses short OAg (S-OAg).

254 Deletion of $r f a L$ results in LPS with core oligosaccharide (OS) lacking OAg. All deletion strains

255 showed a significantly reduced adhesion to lettuce leaves compared to background strain SR11

$256 \Delta 12$ (Figure $5 B$, i.e. means of $56 \%$ for $\Delta w z z, 44 \%$ for $\Delta f e p E, 31 \%$ for $\Delta w z z \Delta f e p E$, and $50 \%$ for

$257 \Delta r f a L)$. Hence, the heterogeneous distribution of L-OAg and VL-OAg on the bacterial surface is

258 an important factor in the adhesion to lettuce leaves. 
03.04.2020

Salmonella Typhimurium adhesion to lettuce

\section{Discussion}

261 Here we addressed which factors of S. enterica are involved in adhesion to plant surfaces using a

262 reductionist, synthetic approach with controlled surface expression of specific adhesive

263 structures. All known adhesive structures encoded by STM were tested for their impact in

264 adhesion to lettuce leaves. The results of this study are summarized in Figure 6.

265 The involvement of flagella of STM in adhesion to various salad species has been investigated

266 before in several studies that reported decreased adhesion to basil, lettuce, and corn salad leaves

267 for mutant strains lacking the flagella filament $(7,28,37)$. These results are in line with our

268 findings for decreased adhesion to lettuce leaves of an STM mutant strain lacking flagella

269 filaments. Y. Rossez et al. (34) investigated the binding of pathogenic and nonpathogenic E. coli

270 strains on a molecular level, revealing ionic binding of sulphated and phosphorylated plasma

271 membrane lipids on Arabidopsis thaliana leaves. Whether the STM flagella filament also binds

272 these molecules still has to be investigated. In addition to the flagella filament, Kroupitski et al.

273 (7) found a contribution of chemotaxis, since a $\Delta c h e Y$ strain (only smooth swimming) showed

274 decreased internalization in lettuce leaves. These authors hypothesized that lack of chemotaxis to

275 higher sucrose concentrations close to stomata is affected, whereas the initial attachment of

276 lettuce leaves was not affected. We investigated the involvement of motility in adhesion to lettuce

277 leaves. A decreased adhesion was shown for strains deficient in energization and switching from

$278 \mathrm{CCW}$ to $\mathrm{CW}$ flagella rotation ('run only'), thus indicating the importance of directed motility and

279 the capability of stopping on the leave surfaces. Bacteria only smooth swimming are probably not

280 able to efficiently contact the leaf surface, or the initial adhesion is disrupted by the force

281 generated by flagella rotating CCW. In summary, STM adhesion to lettuce leaves depends on 
bioRxiv preprint doi: https://doi.org/10.1101/2020.04.03.024968; this version posted April 5, 2020. The copyright holder for this preprint (which

was not certified by peer review) is the author/funder, who has granted bioRxiv a license to display the preprint in perpetuity. It is made available under aCC-BY-NC-ND 4.0 International license.

03.04.2020

Salmonella Typhimurium adhesion to lettuce

motility, and in particular on the ability to switch flagella rotation from $\mathrm{CCW}$ (run) to $\mathrm{CW}$

283 (tumble).

284 The contribution of LPS of STM to virulence was investigated for mammalian cells in several 285 studies before $(38,39)$. However, less is known about the involvement of STM LPS in adhesion 286 to plants. In this study, we elucidated the importance of LPS with full length O-antigen for STM 287 adhesion to lettuce leaves. The data indicate that LPS exhibits either specific binding properties 288 for lettuce leaves or more probable, the surface charge and/or hydrophilicity of STM with intact 289 LPS leads to an adhesion to lettuce leaves. This explanation for our finding of STM LPS 290 involvement in adhesion to corn salad leaves is in line with a previous study (28). In studies on 291 adhesion of pathogenic E. coli, lower attachment of LPS mutants to A. thaliana and romaine 292 lettuce leaves was observed (40), indicating the importance of LPS in general for adhesion to 293 plants. Further, M. H. de Moraes et al. (41) showed the involvement of STM LPS also for the 294 persistence in tomatoes, revealing an impact in the entire infection process. However, changes of 295 the bacterial cell surface charge due to altered LPS structure were not shown yet, but changes in 296 biofilm formation were observed for bacterial plant pathogens with altered LPS structure. For 297 example, altered LPS structure of $P$. aeruginosa caused decreased biofilm formation and affected 298 virulence (42). Nevertheless, the involvement of LPS of STM in adhesion to plants, and effects of 299 altered O-antigen structure on surface properties have to be further investigated.

300 In addition, the expression of fimbrial adhesins revealed increased adhesion to lettuce leaves if 301 Sti or Lpf fimbriae were expressed. While expression was observed during infection of bovine 302 ligated ileal loops (11), no specific ligands are knowns so far for Sti or Lpf. Whereas Sti fimbriae 303 are absent in S. enterica serovar Typhi and in some strains of serovar Paratyphi A, Lpf are 304 restricted to Typhimurium (43). A. J. Bäumler et al. (44) showed the involvement of Lpf fimbriae 305 in adhesion to murine Peyer's patches and to HEp-2 cells (44), and Lpf fimbriae contribute to 
bioRxiv preprint doi: https://doi.org/10.1101/2020.04.03.024968; this version posted April 5, 2020. The copyright holder for this preprint (which

was not certified by peer review) is the author/funder, who has granted bioRxiv a license to display the preprint in perpetuity. It is made available under aCC-BY-NC-ND 4.0 International license.

03.04.2020

Salmonella Typhimurium adhesion to lettuce

306 long-term intestinal colonization of STM in resistant mice (45). Additionally, N. A. Ledeboer et

307 al. (14) revealed 10-fold increased amounts of LpfE in biofilms, leading to the assumption that

308 Lpf fimbriae are involved in biofilm formation during microcolony stage. Moreover, deletion of

309 Lpf fimbriae resulted in loss of biofilm formation on chicken intestine. As for Lpf fimbriae, little

310 is known about Sti fimbriae. A study by P. Laniewski et al. (46) revealed the involvement of Sti,

311 Saf, Stc and curli fimbriae in murine infection model. Deletion of all four fimbrial operons

312 resulted in a strain attenuated in a murine infection model, but if only one operon was deleted, no

313 effect was observed. This indicates a possible redundancy of these fimbriae in murine infection,

314 which were not observed for adhesion to lettuce leaves. Binding properties of Sti and Lpf

315 fimbriae have to be further investigated, i.e. by glycoarrays (15).

316 Deletion of SPI4 encoding SiiE and its cognate T1SS led to an increased adhesion, whereas

317 overexpression of SPI4 genes by overexpression of regulator hilD did not alter adhesion

318 compared to background strain. These results indicate a contribution of SiiE for the whole

319 bacterial population in STM adhesion to lettuce leaves. The same results were observed for

320 adhesion to corn salad leaves (28).

321 We showed the involvement of BapA in adhesion to lettuce leaves. Whereas binding properties

322 for specific glycostructures of BapA remain unclear, several studies revealed a contribution of

323 BapA in biofilm formation $(17,22)$. Data obtained in this study after infection for $1 \mathrm{~h}$ were

324 independent of biofilm formation by BapA. In our previous study, we revealed the involvement

325 of BapA expression in adhesion to corn salad leaves leading to increased adhesion compared to

326 background strain (28). Further, we tested the involvement of various BIg domains by using

327 truncated forms of BapA and revealed a length-dependent adhesion of BapA to corn salad leaves,

328 which was reduced by deletion of at least one BIg domain. Testing similar truncated forms of

329 BapA in adhesion to lettuce leaves revealed suggested as similar role for BIg28, since binding 
bioRxiv preprint doi: https://doi.org/10.1101/2020.04.03.024968; this version posted April 5, 2020. The copyright holder for this preprint (which

was not certified by peer review) is the author/funder, who has granted bioRxiv a license to display the preprint in perpetuity. It is made available under aCC-BY-NC-ND 4.0 International license.

03.04.2020

Salmonella Typhimurium adhesion to lettuce

330 mediated by BapA $\triangle \mathrm{BIg} 28$ was reduced to the level of the background strain. In contrast,

331 deletion of BIg1 did not affect adhesion compared to WT BapA. These observations indicate

332 BIg-specific binding properties of BapA. However, the BapA topology has to be taken into

333 consideration. While BIg28 is likely most distal to the outer membrane core, BIg1 is most

334 proximal to the outer membrane and less likely to contact potential ligands. Moreover, bapABCD

335 is highly conserved among S. enterica serovars (with some variations in bapA) indicating an

336 important purpose during S. enterica lifestyle (47). Contribution of BapA encoded by other

337 S. enterica serovars in adhesion to various salad species has to be tested in addition to the

338 influence of longer infection times and involvement of BapA affecting biofilm formation on salad

339 leaves. Here, we suggest to general role of STM BapA in adhesion to salad species.

340 In this study, we showed an involvement of autotransported MisL in adhesion to lettuce leaves.

341 Expression of MisL is known to facilitates adhesion to $\mathrm{CaCo} 2$ and $\mathrm{HeLa}$ cells, enhancing biofilm

342 formation (48), and contributing to intestinal colonization of mice (24). Furthermore, binding

343 specificity of the non-conserved passenger domain (aa29-281) for fibronectin and, with lower

344 affinity for collagen IV, were determined in extracellular matrix protein-binding assays (24).

345 Deletion of the non-conserved transporter domain led to adhesion comparable to background

346 strain indicating an involvement of fibronectin or collagen IV binding in adhesion to lettuce

347 leaves. Purification of plant cell wall of Pisum sativum (peas) revealed a fibronectin-like protein

348 (49), that may act as potentially ligands for MisL. However, direct contact to the plant cell wall

349 for attaching bacteria is unlikely due to the barrier of overlaying epicuticular waxes. ShdA which

350 is also known for fibronectin binding (50), showed no increased adhesion to lettuce leaves.

351 Therefore, the ligand for MisL on lettuce leaves remains to be identified. The relevance of MisL

352 in colonization of lettuce was previously investigated by Y. Kroupitski et al. (8). A genetic screen

353 identified, together with $s t f C$ (encoding $\mathrm{C} / \mathrm{U}$ fimbriae subunit) and bcsA (cellulose synthase 
03.04.2020

Salmonella Typhimurium adhesion to lettuce

354 subunit), misL as upregulated in STM on lettuce after storage for 7 days at $8{ }^{\circ} \mathrm{C}$. Deletion of $m i s L$

355 led to decreased survival on lettuce leaves under cold storage conditions. Interestingly, the effect

356 of misL on survival was dependent on the presence of lettuce and absent after sole cold storage

357 (8).

358 In this study, we showed for the first time the contribution of directed motility, an intact LPS

359 layer, and expression of various adhesive structures of STM in adhesion to lettuce leaves. We

360 revealed expression of Lpf or Sti fimbriae, T1SS-secreted BapA, or autotransported MisL leads

361 to enhanced adhesion MisL to lettuce leaves. To gain further insight in the adhesion of STM to

362 salad, BapA has to be further investigated possibly revealing common adhesive effects on plants

363 in general. Furthermore, expression of all adhesive structures, especially adhesive structures

364 involved in adhesion to salad, have to be further examined with regard to their native expression.

365 For this purpose, we suggest transcriptomics or proteomics analyses of STM grown under various

366 environmental conditions. In summary, with this work we further contributed to the

367 understanding of the interaction of S. enterica adhesion to salad. 
03.04 .2020

Salmonella Typhimurium adhesion to lettuce

\section{Materials and Methods}

\section{Bacterial strains and culture conditions}

371 Bacterial strains used in this study are listed in Table 1. Unless otherwise stated, bacteria were 372 grown in LB (lysogeny broth) medium, or on LB agar containing antibiotics for selection of

373 specific markers if required to maintain plasmids listed in Table 2. Carbenicillin (Carb) and 374 kanamycin $(\mathrm{Km})$ were used to a final concentration of $50 \mu \mathrm{g} / \mathrm{ml}$. For the induction of the Tet-on 375 system, anhydrotetracycline (AHT) was added ad final concentrations of 10-100 ng/ml.

\section{Construction of strains and plasmids}

377 For the construction of plasmids encoding various truncated forms of misL under the Tet-on 378 system, plasmid p4403 was used as template. The plasmid was amplified by using 379 oligonucleotides listed in Table 2, resulting in lack of various amounts of codons. Amplified 380 products were reassembled by site-directed mutagenesis (SDM) kit according to manufacturer's 381 protocol (NEB). Sequence-confirmed plasmids were electroporated in STM SR11 $\Delta 12$.

\section{Cultivation of sterile grown lettuce and corn salad}

383 Lettuce seeds (Lactuca sativa L. cultivar Tizian) and corn salad seeds (Valerianella locusta Verte

384 à cour plein 2, N.L. Chrestensen Erfurter Samen- und Pflanzenzucht) were kindly provided by

385 Dr. Adam Schikora and Dr. Sven Jechalke (Justus-Liebig University Giessen). Lettuce seeds

386 were sterilized by $3 \% \mathrm{NaClO}$ for $4 \mathrm{~min}$ thereby inverting the tube manually. Further, lettuce

387 seeds were washed four times with sterile $\mathrm{H}_{2} \mathrm{O}_{\mathrm{dd}}$ and directly planted on Murashige-Skoog (MS)

388 agar (per liter: $2.2 \mathrm{~g}$ MS medium including vitamins, Duchefa Biochemie \#M0222; $10 \mathrm{~g}$ agar; $5 \mathrm{~g}$

389 sucrose) in sterile plastic containers with air filter (round model $140 \mathrm{~mm}$; Duchefa Biochemie,

390 \#E1674). Lettuce seeds were kept in the dark for 1 day at RT, and then further cultivated at $20{ }^{\circ} \mathrm{C}$

391 with a 12-h/12-h day-night-rhythm for 4 weeks. Corn salad seeds were sterilized by $70 \%$ EtOH 
03.04.2020

Salmonella Typhimurium adhesion to lettuce

392 for $1 \mathrm{~min}$ followed by $3 \% \mathrm{NaClO}$ for 2 min. Seeds were washed thrice with sterile $\mathrm{H}_{2} \mathrm{O}_{\mathrm{dd}}$ and

393 dried for $30 \mathrm{~min}$. Corn salad seeds were planted on MS agar (2.2 g MS medium including

394 vitamins, Duchefa Biochemie \#M0222; $10 \mathrm{~g}$ agar; $0.5 \mathrm{~g}$ MES per liter; $\mathrm{pH}$ 5.4) in sterile plastic

395 containers with air filter as above at $20^{\circ} \mathrm{C}$ with a $12 \mathrm{~h} / 12 \mathrm{~h}$ day-night-rhythm for 8 weeks.

396 Adhesion to lettuce and corn salad

397 Infection of lettuce with Salmonella was done as previously described in Elpers et al. (28) for

398 infection of corn salad. In short, for each condition and strain three leaf discs of lettuce or corn

399 salad were infected with STM strains diluted 1:31 from o/n cultures for $3.5 \mathrm{~h}$. Infection was

400 performed for $1 \mathrm{~h}$ at RT under static conditions, or for $55 \mathrm{~min}$ at RT after centrifugation of $5 \mathrm{~min}$

401 at $500 \mathrm{x}$ g. After infection, leaf discs were washed with phosphate-buffered saline (PBS),

402 homogenized and lysates were plated on MH (Mueller Hinton) agar plates, and incubated o/n at

$40337^{\circ} \mathrm{C}$. A non-infected sample was used in every assay to ensure sterility of the lettuce or corn

404 salad plants used.

405 Flow Cytometry

406 For analysis of surface expression of MisL by flow cytometry, approximately $6 \times 10^{8}$ bacteria

407 were washed in PBS and then fixed with 3\% paraformaldehyde in PBS for 20 min at RT.

408 Bacteria were blocked with $2 \%$ goat serum in PBS for $30 \mathrm{~min}$ and afterwards stained with the

409 specific primary antiserum rabbit $\alpha \operatorname{MisL}(1: 1,000) \mathrm{o} / \mathrm{n}, 4{ }^{\circ} \mathrm{C}$. Staining with secondary antibody

410 goat $\alpha$ rabbit-Alexa488 (1:2,000) was performed for $1 \mathrm{~h}$ at RT. Bacteria were measured with a

411 Attune NxT Flow Cytometer (Thermo Fisher) and analyzed using Attune NxT software, version

4123.11.

413 Autoaggregation analysis

414 For analysis of autoaggregation of strains expressing MisL and various truncated forms of MisL,

415 subcultures used for the infection of lettuce were diluted to $1 \times 10^{8}$ bacteria/ml in PBS. $7 \mu 1$ of 
03.04.2020

Salmonella Typhimurium adhesion to lettuce

416 bacterial suspension were imaged by Zeiss AxioObserver with brightfield microscopy with a 40x

417 objective. Images were recorded by an AxioCam, and data were analyzed using ZEN 2012.

\section{Acknowledgements}

419 This work was supported by the Bundesanstalt für Landwirtschaft und Ernährung (BLE) by 420 projects PlantInfect and PlantInfect2, grant 2813HS027). Further support by the DFG by grant

421 SFB 944, project Z is kindly acknowledged. We thank the members of the PlantInfect consortium

422 for fruitful discussion and exchange of reagents. The systematic analyses of GEO data for 423 adhesin expression, and critical comment on the manuscript by Janina Noster are gratefully 424 acknowledged. We like to thank Andreas J. Bäumler (UC at Davis) for sharing antiserum against 425 MisL. 
bioRxiv preprint doi: https://doi.org/10.1101/2020.04.03.024968; this version posted April 5, 2020. The copyright holder for this preprint (which

was not certified by peer review) is the author/funder, who has granted bioRxiv a license to display the preprint in perpetuity. It is made available under aCC-BY-NC-ND 4.0 International license.

03.04.2020

Salmonella Typhimurium adhesion to lettuce

\section{References}

429 1. Andino A, Hanning I. 2015. Salmonella enterica: survival, colonization, and virulence differences among serovars. ScientificWorldJournal 2015:520179.

432

433

434

435

436

437

438

439

440

441

442

443

444

445

446

447

448

449

450

451

452

453

454

455

456

457

458

459

460

461

462

463

464

465

466

467

468

469

2. EFSA. 2014. Scientific Opinion on the risk posed by pathogens in food of non-animal origin. Part 2 (Salmonella and Norovirus in leafy greens eaten raw as salads). EFSA Journal 12:3600.

3. Schikora A, Garcia AV, Hirt H. 2012. Plants as alternative hosts for Salmonella. Trends Plant Sci 17:245-9.

4. Hernandez-Reyes C, Schikora A. 2013. Salmonella, a cross-kingdom pathogen infecting humans and plants. FEMS Microbiol Lett 343:1-7.

5. Warner JC, Rothwell SD, Keevil CW. 2008. Use of episcopic differential interference contrast microscopy to identify bacterial biofilms on salad leaves and track colonization by Salmonella Thompson. Environ Microbiol 10:918-25.

6. Jechalke S, Schierstaedt J, Becker M, Flemer B, Grosch R, Smalla K, Schikora A. 2019. Salmonella Establishment in Agricultural Soil and Colonization of Crop Plants Depend on Soil Type and Plant Species. Front Microbiol 10:967.

7. Kroupitski Y, Golberg D, Belausov E, Pinto R, Swartzberg D, Granot D, Sela S. 2009. Internalization of Salmonella enterica in leaves is induced by light and involves chemotaxis and penetration through open stomata. Appl Environ Microbiol 75:6076-86.

8. Kroupitski Y, Brandl MT, Pinto R, Belausov E, Tamir-Ariel D, Burdman S, Sela Saldinger S. 2013. Identification of Salmonella enterica genes with a role in persistence on lettuce leaves during cold storage by recombinase-based in vivo expression technology. Phytopathology 103:362-72.

9. Wagner C, Hensel M. 2011. Adhesive Mechanisms of Salmonella enterica. Linke D, Goldman A (eds) Bacterial Adhesion Advances in Experimental Medicine and Biology 715.

10. Wiedemann A, Virlogeux-Payant I, Chausse AM, Schikora A, Velge P. 2014. Interactions of Salmonella with animals and plants. Front Microbiol 5:791.

11. Humphries AD, Raffatellu M, Winter S, Weening EH, Kingsley RA, Droleskey R, Zhang S, Figueiredo J, Khare S, Nunes J, Adams LG, Tsolis RM, Bäumler AJ. 2003. The use of flow cytometry to detect expression of subunits encoded by 11 Salmonella enterica serotype Typhimurium fimbrial operons. Mol Microbiol 48:1357-76.

12. Thanassi DG, Saulino ET, Hultgren SJ. 1998. The chaperone/usher pathway: a major terminal branch of the general secretory pathway. Curr Opin Microbiol 1:223-31.

13. Kolenda R, Ugorski M, Grzymajlo K. 2019. Everything you always wanted to know about Salmonella type 1 fimbriae, but were afraid to ask. Front Microbiol 10:1017.

14. Ledeboer NA, Frye JG, McClelland M, Jones BD. 2006. Salmonella enterica serovar Typhimurium requires the Lpf, Pef, and Tafi fimbriae for biofilm formation on HEp-2 tissue culture cells and chicken intestinal epithelium. Infect Immun 74:3156-69.

15. Chessa D, Dorsey CW, Winter M, Bäumler AJ. 2008. Binding specificity of Salmonella plasmid-encoded fimbriae assessed by glycomics. J Biol Chem 283:8118-24.

16. Barnhart MM, Chapman MR. 2006. Curli biogenesis and function. Annu Rev Microbiol 470 60:131-47. 
bioRxiv preprint doi: https://doi.org/10.1101/2020.04.03.024968; this version posted April 5, 2020. The copyright holder for this preprint (which

was not certified by peer review) is the author/funder, who has granted bioRxiv a license to display the preprint in perpetuity. It is made available under aCC-BY-NC-ND 4.0 International license.

03.04.2020

Salmonella Typhimurium adhesion to lettuce

471

472

473

474

475

476

477

478

479

480

481

482

483

484

485

486

487

488

489

490

491

492

493

494

495

496

497

498

499

500

501

502

503

504

505

506

507

508

509

510

511

512

513

514

515

516

17. Jonas K, Tomenius H, Kader A, Normark S, Römling U, Belova LM, Melefors O. 2007. Roles of curli, cellulose and BapA in Salmonella biofilm morphology studied by atomic force microscopy. BMC Microbiol 7:70.

18. Gerlach RG, Jäckel D, Stecher B, Wagner C, Lupas A, Hardt WD, Hensel M. 2007. Salmonella Pathogenicity Island 4 encodes a giant non-fimbrial adhesin and the cognate type 1 secretion system. Cell Microbiol 9:1834-50.

19. Wagner C, Barlag B, Gerlach RG, Deiwick J, Hensel M. 2014. The Salmonella enterica giant adhesin SiiE binds to polarized epithelial cells in a lectin-like manner. Cell Microbiol 16:962-75.

20. Gerlach RG, Jäckel D, Geymeier N, Hensel M. 2007. Salmonella pathogenicity island 4mediated adhesion is coregulated with invasion genes in Salmonella enterica. Infect Immun 75:4697-709.

21. Zhang K, Riba A, Nietschke M, Torow N, Repnik U, Putz A, Fulde M, Dupont A, Hensel M, Hornef M. 2018. Minimal SPI1-T3SS effector requirement for Salmonella enterocyte invasion and intracellular proliferation in vivo. PLoS Pathog 14:e1006925.

22. Latasa C, Roux A, Toledo-Arana A, Ghigo JM, Gamazo C, Penades JR, Lasa I. 2005. BapA, a large secreted protein required for biofilm formation and host colonization of Salmonella enterica serovar Enteritidis. Mol Microbiol 58:1322-39.

23. Hansmeier N, Miskiewicz K, Elpers L, Liss V, Hensel M, Sterzenbach T. 2017. Functional expression of the entire adhesiome of Salmonella enterica serotype Typhimurium. Sci Rep 7:10326.

24. Dorsey CW, Laarakker MC, Humphries AD, Weening EH, Baumler AJ. 2005. Salmonella enterica serotype Typhimurium MisL is an intestinal colonization factor that binds fibronectin. Mol Microbiol 57:196-211.

25. Kingsley RA, Santos RL, Keestra AM, Adams LG, Bäumler AJ. 2002. Salmonella enterica serotype Typhimurium ShdA is an outer membrane fibronectin-binding protein that is expressed in the intestine. Mol Microbiol 43:895-905.

26. Tukel C, Akcelik M, de Jong MF, Simsek O, Tsolis RM, Bäumler AJ. 2007. MarT activates expression of the MisL autotransporter protein of Salmonella enterica serotype Typhimurium. J Bacteriol 189:3922-6.

27. Raghunathan D, Wells TJ, Morris FC, Shaw RK, Bobat S, Peters SE, Paterson GK, Jensen KT, Leyton DL, Blair JM, Browning DF, Pravin J, Flores-Langarica A, Hitchcock JR, Moraes CT, Piazza RM, Maskell DJ, Webber MA, May RC, MacLennan CA, Piddock LJ, Cunningham AF, Henderson IR. 2011. SadA, a trimeric autotransporter from Salmonella enterica serovar Typhimurium, can promote biofilm formation and provides limited protection against infection. Infect Immun 79:4342-52.

28. Elpers L, Kretzschmar J, Nuccio SP, Bäumler AJ, Hensel M. 2020. Systematic analyses of factors required for adhesion of Salmonella enterica serovar Typhimurium to corn salad (Valerianella locusta). Appl Environ Microbiol doi:10.1128/AEM.0275719:AEM.02757-19.

29. Edgar R, Domrachev M, Lash AE. 2002. Gene Expression Omnibus: NCBI gene expression and hybridization array data repository. Nucleic Acids Res 30:207-10.

30. Kröger C, Colgan A, Srikumar S, Handler K, Sivasankaran SK, Hammarlof DL, Canals R, Grissom JE, Conway T, Hokamp K, Hinton JC. 2013. An infection-relevant transcriptomic compendium for Salmonella enterica Serovar Typhimurium. Cell Host Microbe 14:683-95. 
bioRxiv preprint doi: https://doi.org/10.1101/2020.04.03.024968; this version posted April 5, 2020. The copyright holder for this preprint (which

was not certified by peer review) is the author/funder, who has granted bioRxiv a license to display the preprint in perpetuity. It is made available under aCC-BY-NC-ND 4.0 International license.

03.04.2020

Salmonella Typhimurium adhesion to lettuce

517

518

519

520

521

522

523

524

525

526

527

528

529

530

531

532

533

534

535

536

537

538

539

540

541

542

543

544

545

546

547

548

549

550

551

552

553

554

555

556

557

558

559

560

561

562

563

31. Main-Hester KL, Colpitts KM, Thomas GA, Fang FC, Libby SJ. 2008. Coordinate regulation of Salmonella pathogenicity island 1 (SPI) and SPI4 in Salmonella enterica serovar Typhimurium. Infect Immun 76:1024-35.

32. Lambert MA, Smith SG. 2009. The PagN protein mediates invasion via interaction with proteoglycan. FEMS Microbiol Lett 297:209-16.

33. Rosselin M, Virlogeux-Payant I, Roy C, Bottreau E, Sizaret PY, Mijouin L, Germon P, Caron E, Velge P, Wiedemann A. 2010. Rck of Salmonella enterica, subspecies enterica serovar enteritidis, mediates zipper-like internalization. Cell Res 20:647-64.

34. Rossez Y, Holmes A, Wolfson EB, Gally DL, Mahajan A, Pedersen HL, Willats WG, Toth IK, Holden NJ. 2014. Flagella interact with ionic plant lipids to mediate adherence of pathogenic Escherichia coli to fresh produce plants. Environ Microbiol 16:2181-95.

35. Tan MS, White AP, Rahman S, Dykes GA. 2016. Role of fimbriae, flagella and cellulose on the attachment of Salmonella Typhimurium ATCC 14028 to plant cell wall models. PLoS One 11:e0158311.

36. Kutschera A, Ranf S. 2019. The multifaceted functions of lipopolysaccharide in plantbacteria interactions. Biochimie 159:93-98.

37. Berger CN, Shaw RK, Brown DJ, Mather H, Clare S, Dougan G, Pallen MJ, Frankel G. 2009. Interaction of Salmonella enterica with basil and other salad leaves. ISME J 3:2615.

38. Hölzer SU, Schlumberger MC, Jäckel D, Hensel M. 2009. Effect of the O-antigen length of lipopolysaccharide on the functions of Type III secretion systems in Salmonella enterica. Infect Immun 77:5458-70.

39. Matamouros S, Miller SI. 2015. S. Typhimurium strategies to resist killing by cationic antimicrobial peptides. Biochim Biophys Acta 1848:3021-5.

40. Jang H, Matthews KR. 2018. Influence of surface polysaccharides of Escherichia coli O157:H7 on plant defense response and survival of the human enteric pathogen on Arabidopsis thaliana and lettuce (Lactuca sativa). Food Microbiol 70:254-261.

41. de Moraes MH, Desai P, Porwollik S, Canals R, Perez DR, Chu W, McClelland M, Teplitski M. 2017. Salmonella persistence in tomatoes requires a distinct set of metabolic functions identified by transposon insertion sequencing. Appl Environ Microbiol 83.

42. Bogino PC, Oliva Mde L, Sorroche FG, Giordano W. 2013. The role of bacterial biofilms and surface components in plant-bacterial associations. Int J Mol Sci 14:15838-59.

43. Yue M, Rankin SC, Blanchet RT, Nulton JD, Edwards RA, Schifferli DM. 2012. Diversification of the Salmonella fimbriae: a model of macro- and microevolution. PLoS One 7:e38596.

44. Bäumler AJ, Tsolis RM, Heffron F. 1996. The lpf fimbrial operon mediates adhesion of Salmonella typhimurium to murine Peyer's patches. Proc Natl Acad Sci U S A 93:279-83.

45. Weening EH, Barker JD, Laarakker MC, Humphries AD, Tsolis RM, Bäumler AJ. 2005. The Salmonella enterica serotype Typhimurium $l p f, b c f, s t b$, stc, std, and sth fimbrial operons are required for intestinal persistence in mice. Infect Immun 73:3358-66.

46. Laniewski P, Baek CH, Roland KL, Curtiss R, 3rd. 2017. Analysis of spleen-induced fimbria production in recombinant attenuated Salmonella enterica serovar Typhimurium vaccine strains. MBio 8.

47. Velasquez JC, Hidalgo AA, Villagra N, Santiviago CA, Mora GC, Fuentes JA. 2016. SPI9 of Salmonella enterica serovar Typhi is constituted by an operon positively regulated by RpoS and contributes to adherence to epithelial cells in culture. Microbiology 162:136778. 
564 48. Wang S, Yang D, Wu X, Wang Y, Wang D, Tian M, Li T, Qi J, Wang X, Ding C, Yu S. 2018. Autotransporter MisL of Salmonella enterica serotype Typhimurium facilitates bacterial aggregation and biofilm formation. FEMS Microbiol Lett 365.

49. Pellenc D, Schmitt E, Gallet O. 2004. Purification of a plant cell wall fibronectin-like adhesion protein involved in plant response to salt stress. Protein Expr Purif 34:208-14.

50. Kingsley RA, Santos RL, Keestra AM, Adams LG, Baumler AJ. 2002. Salmonella enterica serotype Typhimurium ShdA is an outer membrane fibronectin-binding protein that is expressed in the intestine. Mol Microbiol 43:895-905.

51. Schneider HA, Zinder ND. 1956. Nutrition of the host and natural resistance to infection. V. An improved assay employing genetic markers in the double strain inoculation test. J Exp Med 103:207-23. 
03.04.2020 Salmonella Typhimurium adhesion to lettuce

\section{Tables}

\section{Table 1. Bacterial strains used in this study}

578 Designation

579 E. coli NEB5 $\alpha$

580 S. Typhimurium NCTC

$581 \quad 12023$

$582 \quad S$. Typhimurium SR11 wild type

$583 \quad$ SPN376

$584 \quad(=\mathrm{SR} 11 \Delta 12)$

585

586

$587 \quad$ MvP2447

588 MvP2506

$589 \quad \mathrm{MvP} 2507$

$590 \quad$ MvP2622

$591 \quad$ MvP2623

$592 \quad$ MvP2624

$593 \quad \mathrm{MvP} 2625$

$594 \quad$ MvP2703

$595 \quad$ MvP2707 (= $=20)$
Relevant characteristics

Cloning strain

$S$. Typhimurium wild type

$\triangle$ fimAICDHF $\triangle$ stbABCD $\triangle$ sthABCDE

$\triangle$ stfACDEFG $\triangle$ stiABCH $\triangle b c f A B C D E F G H$

$\triangle s a f A B C D \triangle p e f A C D$ orf5orf6 $\triangle s t c A B C D$

$\triangle s t j E D C B A \triangle s t d A B \triangle l p f A B C D E:: \mathrm{KSac}$

$\Delta 12$ misL::FRT

$\Delta 12$ rck::aph I-SceI

$\Delta 12$ pagN::aph I-SceI

$\Delta 12$ shdA::aph

$\Delta 12$ sadA::aph

$\Delta 12$ SPI4::aph

$\triangle 12 \operatorname{csg} B A C:: a p h$

$\triangle 12 \Delta m i s L \triangle$ sadA $\triangle$ shdA $\triangle$ SPI4 $\triangle$ bapABCD 
03.04.2020

Salmonella Typhimurium adhesion to lettuce

$597 \quad$ MvP2710

$\Delta 12 \Delta$ misL $\triangle$ sadA $\triangle$ shdA $\triangle$ SPI4 $\triangle b a p A B C D$

598

$\Delta r c k \triangle p a g N \triangle \operatorname{csg} B A C-D E F G \triangle f l i I:: a p h$

$599 \quad$ MvP2711

$\triangle 12 \Delta m i s L \Delta s a d A \Delta s h d A \triangle$ SPI4 $\triangle b a p A B C D$

600

$\triangle r c k \triangle p a g N \triangle \operatorname{csg} B A C-D E F G \triangle m o t A B:: a p h$

$601 \quad \mathrm{MvP} 2718$

$\Delta 12$ invC::aph

$602 \quad$ MvP2751

$\Delta 12$ cheZ::aph

$603 \quad \mathrm{MvP} 2754$

$\Delta 12$ cheY::aph

$604 \quad$ MvP2757

$\Delta 12$ motAB::aph

$605 \quad \mathrm{MvP} 2763$

$\Delta 12$ fliC::FRT fljB::aph

$606 \quad \mathrm{MvP} 2798$

$\Delta 12$ fepE::FRT

607 MvP2799

$\Delta 12 w z z_{\mathrm{ST}}:: F R T$

608 MvP2800

$\triangle 12 r f a L:: F R T$

$609 \quad \mathrm{MvP} 2812$

$\Delta 12$ wzzsT::aph fepE::FRT

$610 \quad$ MvP2844

$\Delta 12$ sopB::FRT sopA::FRT sopE2::FRT

611 (=SR11 $\Delta$ effector proteins) sopD::FRT sipA::aph

612

613 Table 2. Plasmids used in this study

614 Plasmid Relevant characteristics $\quad$ Reference

$615 \mathrm{p} 4253 \quad$ tetR $\mathrm{P}_{\text {tetA }}:$ :bapABCD in pWSK29

$616 \mathrm{p} 4380 \quad$ tetR $\mathrm{P}_{\text {tetA }}:: \operatorname{csg} B A C E F G$ in $\mathrm{pWSK} 29$

$617 \mathrm{p} 4389 \quad$ tetR $\mathrm{P}_{\text {teta }}::$ stiABCD in pWSK29 


\begin{tabular}{|c|c|c|}
\hline 618 & p4390 & tetR $\mathrm{P}_{\text {tetA }}:: s t f A B C D E F G$ in $\mathrm{pWSK} 29$ \\
\hline 619 & p4391 & tetR $\mathrm{P}_{\text {tetA }}:: s t b A B C D E F G$ in pWSK29 \\
\hline 620 & p4392 & tetR $\mathrm{P}_{\text {tetA }}:$ :fimAICDHF in pWSK29 \\
\hline 621 & p4393 & tetR $\mathrm{P}_{\text {tet } A}:: s a f A B C D$ in $\mathrm{pWSK} 29$ \\
\hline 622 & p4394 & tetR $\mathrm{P}_{\text {tetA }}:: s t d A B C D$ in $\mathrm{pWSK} 29$ \\
\hline 623 & p4395 & tetR $\mathrm{P}_{\text {tetA }}:: s t j A B C D E$ in $\mathrm{pWSK} 29$ \\
\hline 624 & p4396 & tetR $\mathrm{P}_{\text {tetA }}:: p e f A C D E F$ in pWSK29 \\
\hline 625 & p4397 & tetR $\mathrm{P}_{\text {tetA }}:: b c f A B C D E F G$ in pWSK29 \\
\hline 626 & p4399 & tetR $\mathrm{P}_{\text {tetA }}:: s t c A B C$ in pWSK29 \\
\hline 627 & $\mathrm{p} 4400$ & tetR $\mathrm{P}_{\text {teta }}:: s t h A B C D E$ in pWSK29 \\
\hline 628 & p4401 & tetR $\mathrm{P}_{\text {tet }}:: p a g N$ in $\mathrm{pWSK} 29$ \\
\hline 629 & p4402 & tetR $\mathrm{P}_{\text {tetA }}:: r c k$ in pWSK29 \\
\hline 630 & $\mathrm{p} 4403$ & tetR $\mathrm{P}_{\text {tetA }}:: m i s L$ in pWSK29 \\
\hline 631 & $\mathrm{p} 4519$ & tetR $\mathrm{P}_{\text {tetA }}::$ lpfABCDE in pWSK29 \\
\hline 632 & $\mathrm{p} 4520$ & tetR $\mathrm{P}_{\text {tetA }}:: s h d A$ in pWSK29 \\
\hline 633 & p4904 & tetR $\mathrm{P}_{\text {teta }}:: h i l D$ in $\mathrm{pWSK} 29$ \\
\hline 634 & p5035 & tetR $\mathrm{P}_{\text {tetA }}:: s a d B A$ in pWSK29 \\
\hline 635 & p4318 & $\mathrm{p} 4253$ bapA $\Delta \mathrm{BIg} 1$ \\
\hline 636 & $\mathrm{p} 4321$ & p4253 bapA $\Delta$ BIg28 \\
\hline 637 & $\mathrm{p} 4331$ & p4253 bapA $\Delta \mathrm{BIg} 1-28$ \\
\hline 63 & p5287 & p4403 misL $\Delta$ aa29-227 \\
\hline
\end{tabular}


bioRxiv preprint doi: https://doi.org/10.1101/2020.04.03.024968; this version posted April 5, 2020. The copyright holder for this preprint (which was not certified by peer review) is the author/funder, who has granted bioRxiv a license to display the preprint in perpetuity. It is made available under aCC-BY-NC-ND 4.0 International license.

03.04 .2020

Salmonella Typhimurium adhesion to lettuce

$639 \quad \mathrm{p} 5288$

p4403 misL $\Delta$ aa29-479

This study

640

641 Table 3. Oligonucleotides used in this study

642 Designation Sequence $\left(3^{\prime} \rightarrow 5^{\prime}\right)$

Purpose

643 Vr-MisL-29 CCAGGCCGCCTGGGAGGG

SDM of p4403

644 Vf-MisL-229 ACTACCGGCGACAGTTCG

SDM of p4403

645 Vf-MisL-481 GATGATGATTCCGAAACGG

SDM of $\mathrm{p} 4403$

646 
03.04.2020

Salmonella Typhimurium adhesion to lettuce

\section{Figure legends}

648 Figure 1: Impact of genes encoding putative adhesive structures and effector proteins of SPI1-T3SS

649 on adhesion of STM to lettuce. Lettuce was grown under aseptic conditions, leave disks were generated, 650 and infected with STM SR11 $\Delta 12$, or various SR11 $\Delta 12$ strains with additional deletions in genes 651 encoding putative adhesive structures, and effector proteins of the SPI1-T3SS ( $\triangle \operatorname{sop} A \Delta \operatorname{sop} B \Delta \operatorname{sopD}$ $652 \triangle \operatorname{sopE2} \triangle \operatorname{sip} A=\Delta$ effector proteins). Overnight cultures were diluted 1:31 in fresh LB, bacteria were 653 subcultured for $3.5 \mathrm{~h}$ and diluted in PBS for infection of lettuce leave disks. After infection for $1 \mathrm{~h}$, lettuce 654 leave disks were washed three times to remove non-adherent bacteria. For the quantification of adherent 655 bacteria, leave disks were homogenized in PBS containing 1\% deoxycholate, and serial dilutions of the 656 homogenate and inoculum were plated onto MH agar plates for the quantification of CFU. Levels of 657 adhesion were determined as percentage of inoculum CFU recovered in leave disk homogenates, and 658 adhesion of various strains was normalized SR11 $\Delta 12$ set to $100 \%$ adhesion. The distributions of three 659 biological replicates is represented as box plots with means and median values. Statistical significances 660 were calculated by the Student's $t$ test and are indicated as follows: n.s., not significant; *, $P<0.05 ; * *, P$ $661<0.01 ; * * *, P<0.001$.

664 lettuce. Sterile grown lettuce was infected with STM SR11 $\Delta 12$, of STM SR11 $\Delta 12$ strains harboring 665 plasmids for the expression of various chaperone-usher fimbriae (A), or curli fimbriae (B). If indicated, 666 expression of fimbriae was induced by addition of $10 \mathrm{ng} / \mathrm{ml}$ AHT during subculture for $3.5 \mathrm{~h}$. The mean 667 levels of adhesion and statistical significances were determined and expressed as described in Figure 1.

669 Figure 3: Impact of T1SS-secreted adhesins and hilD expression on adhesion of STM to lettuce. A)

670 Lettuce grown under aseptic conditions was infected with STM strain SR11 $\Delta 12$ with overexpression of 
03.04.2020

Salmonella Typhimurium adhesion to lettuce

671 regulator hilD for analysis of the SPI4-encoded T1SS-secreted adhesin SiiE, and the SPI1-encoded T3SS.

672 B) Adhesion of SR11 $\Delta 12$ stains with surface expression of T1SS-secreted adhesin BapA or truncated

673 forms of BapA. Expression of adhesins was induced by addition of AHT if indicated. The mean levels of 674 adhesion and statistical significances were determined as described in Figure 1.

676 Figure 4: Impact of T5SS-secreted adhesins and outer membrane proteins on adhesion of STM to

677 lettuce. Lettuce grown under aseptic conditions was infected with STM strain SR11 $\Delta 12$, or STM strain

678 SR11 $\Delta 12$ with surface expression of T5SS-secreted adhesins ShdA or SadA (A), or MisL or truncated

679 forms of MisL (B). Expression of the adhesins was induced by addition of AHT if indicated. C) Models

680 for WT MisL and various truncated forms used in adhesion assays. D) For the analysis of outer membrane

681 proteins, SR11 $\Delta 12$ strains expressing $r c k$ or $p a g N$ by induction of AHT were used. The mean levels of

682 adhesion and statistical significances were determined as described in Figure 1.

683

684 Figure 5: Impact of defects in motility or flagella assembly, or alteration in O-antigen length on

685 STM adhesion to lettuce. A) Lettuce grown under aseptic conditions was infected with STM SR11 $\Delta 12$,

686 or STM SR11 $\Delta 12$ with deletion of various genes required for motility or flagella-associated. B) Effect of

687 mutations in genes resulting in lack $(r f a L)$ or various truncations of O-antigen length ( $w z z_{\mathrm{ST}}, f e p E$, wzz $z_{\mathrm{ST}}$

$688 f e p E$ ). Infection was performed under static conditions (A, B), or by forced contact by centrifugation at

$689500 \mathrm{x} \mathrm{g}$ for $5 \mathrm{~min}$ to compensate effects of mutations in motility genes (A). The adhesion and the 690 statistical significances were determined as described in Figure 1.

691

692 Figure 6: Overview of the role of analyzed factors in adhesion of STM to lettuce leaves. The absence

693 of underlining indicates static samples, and underlining indicates centrifuged samples (forced contact). 
bioRxiv preprint doi: https://doi.org/10.1101/2020.04.03.024968; this version posted April 5, 2020. The copyright holder for this preprint (which was not certified by peer review) is the author/funder, who has granted bioRxiv a license to display the preprint in perpetuity. It is made available under aCC-BY-NC-ND 4.0 International license.

03.04.2020

Salmonella Typhimurium adhesion to lettuce

694 Arrows indicate increased (green) or decreased (red) adhesion, and circles indicate that adhesion was not

695 altered. OM, outer membrane; PP, periplasm; IM, inner membrane; CP, cytoplasm. 


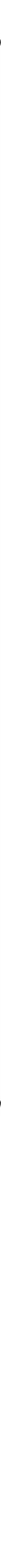




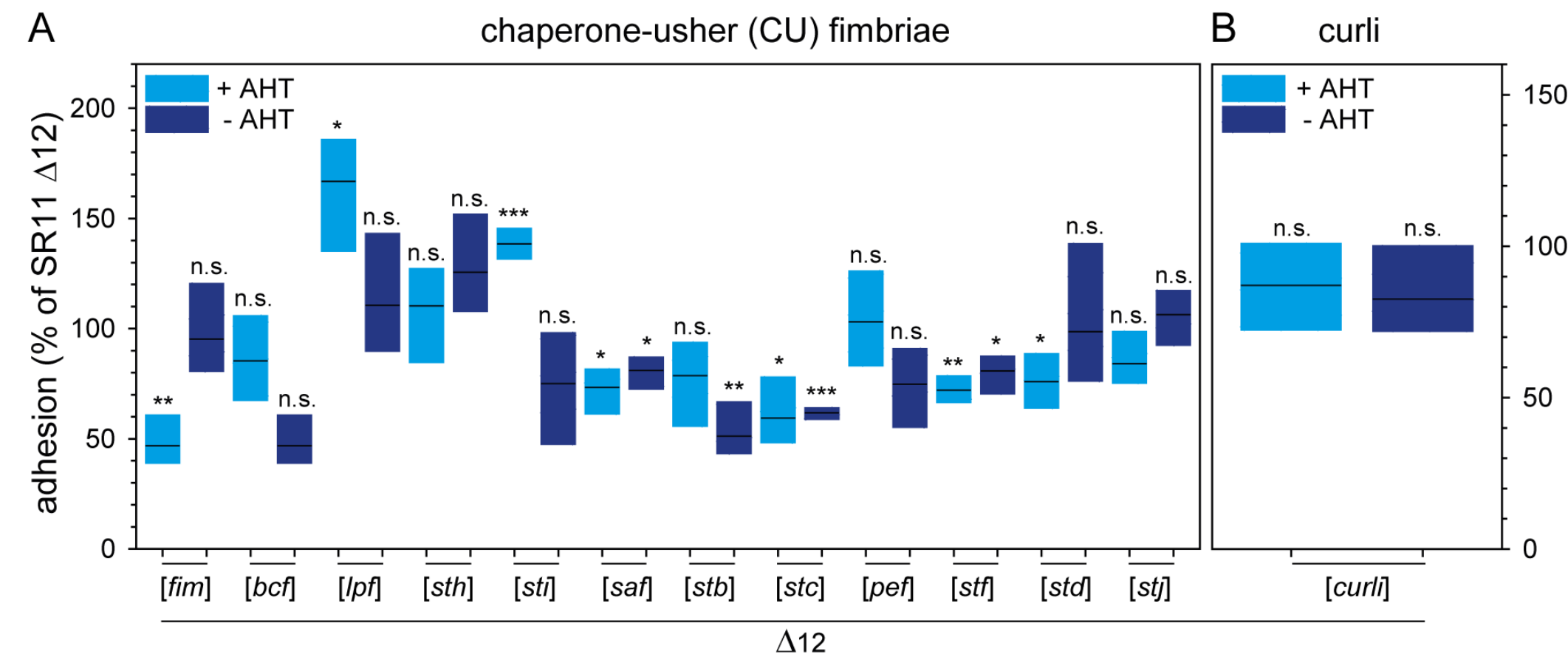


flagella and motility

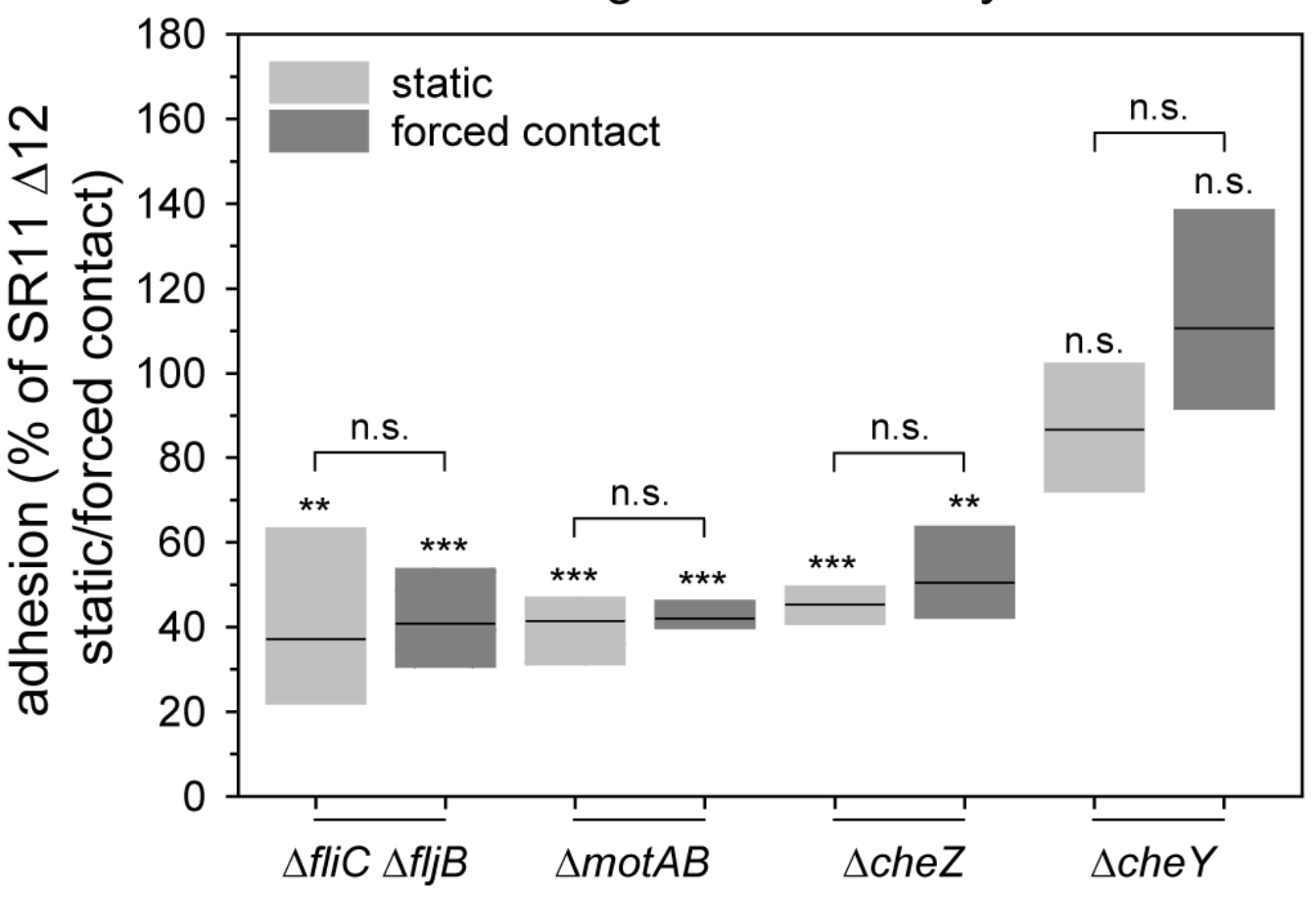

B LPS

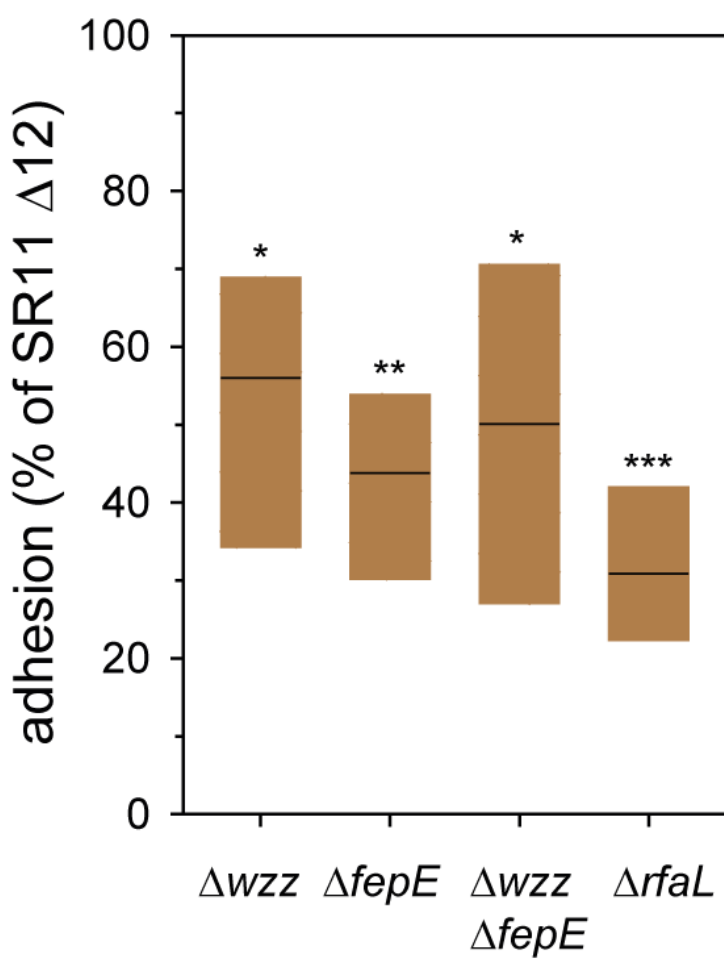




T1SS + T3SS
† BapA, $\Delta$ SPI4
o $\Delta$ effector proteins,
$\quad \Delta$ invC
$\downarrow$ SiiE + SPI1-T3SS

\begin{tabular}{c}
\hline T5SS \\
$\uparrow$ MisL, $\Delta$ misL \\
○ SadA \\
$\downarrow$ ShdA, $\Delta s h d A$ \\
$\Delta s a d A$
\end{tabular}

LPS
$\downarrow \Delta w z z, \Delta f e p E$,
$\Delta w z z \Delta f e p E, \Delta r f a L$

.
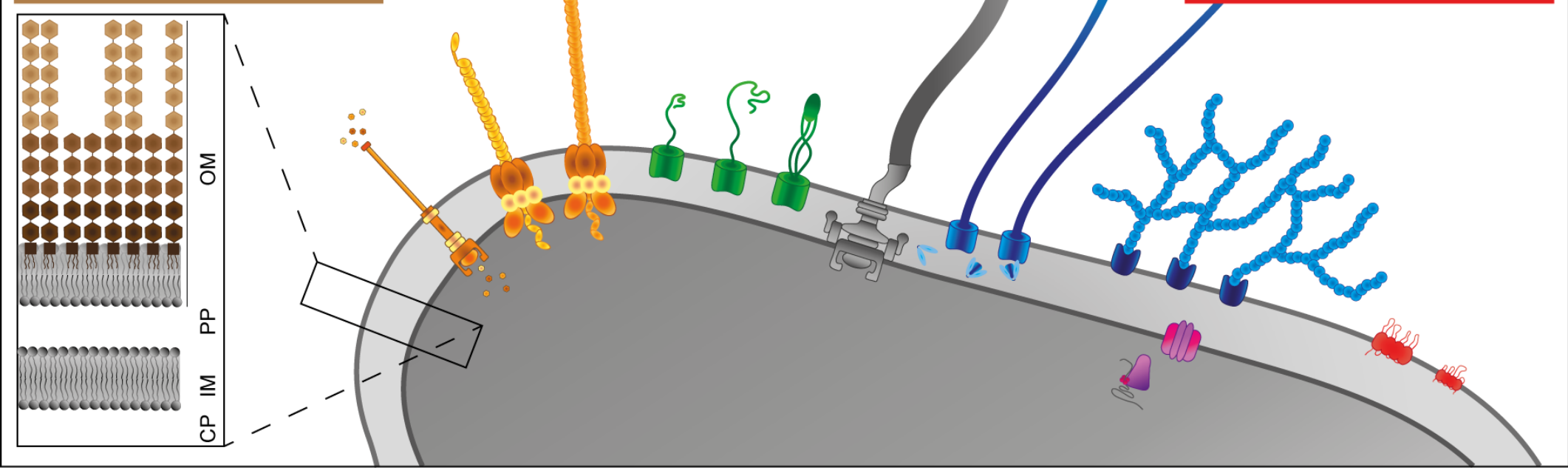